\title{
Learning from Mixed OR Method Practice: The NINES Case Study
}

\author{
Susan Howick ${ }^{1}$, Fran Ackermann ${ }^{1}$, Lesley Walls ${ }^{1}$, John Quigley ${ }^{1}$, Tom Houghton ${ }^{2}$, \\ ${ }^{1}$ University of Strathclyde, ${ }^{2}$ Curtin University
}

Abstract: Despite continued interest in the use of mixed OR/MS methods, limited attention has been paid in the literature to generic lessons that could be gained from mixing methods in practice. Many organisational problems demand the use of a mixed method approach and thus recognising and sharing lessons could prove beneficial to both practitioners and researchers. This paper reports on an in-depth evaluation of a case study involving risk identification and quantification of the Northern Isles New Energy Solutions (NINES) project which sought to trial and plan a new energy system. The intervention involved a mixed method approach and client feedback on the efficacy of the approach was sought. The evaluation reported in this paper is carried out using a set of themes taken from the literature and seeks to highlight transferable lessons. The set of lessons that emerge are presented along with their implications for both general OR modelling practice and the specific situation of mixing OR/MS methods. The paper concludes by discussing the implications of the work and directions for future work which will be of interest to both practitioners and researchers interested in mixed method OR/MS work.

Keywords: Mixed Methods; Causal mapping; Decision tree; Evaluation; Case Study; Risk analysis

\section{Introduction}

Over the last two decades there has been continued interest in work that involves mixing OR/MS methods, stemming predominantly from the well documented assertion of their associated benefits (for example Mingers and Brocklesby, 1997; Jackson, 1999; Mingers, 2000; Mingers, 2003; Pollack 2009, Franco and Lord 2011, Howick and Ackermann 2011, Morgan 2013, Heano \& Franco 2016 ). For example, Mingers (2000) argues strongly that one of the reasons that mixing methods is desirable is 'to generate a richer and more effective way of handling the problem situation' (our emphasis page 679). Moreover, it has been asserted that real world problems are becoming increasingly complex and multi-dimensional and amongst other considerations, go through a number of phases suggesting the use of multiple methods. The complexities of real problems thus reinforce the use of mixed methods in practice (Mingers, 2001; Pidd, 2004; Mingers and Gill, 2007), so that a wider set of methods and associated tools and techniques can assist in problem resolution.

Despite however the continued interest in work in this area, it has been recognised that there has been limited attention paid in the literature to generic lessons that could be gained from mixing methods in practice (Howick and Ackermann, 2011). As noted above, many organizational problems demand the use of a mixed method approach and thus recognising and sharing generic lessons could prove beneficial to both practitioners and researchers.

As a first step towards articulating generic lessons, Howick and Ackermann (2011) examined a number of published OR mixed method case studies. This work was guided by a set of emergent themes which enabled a range of researchers' experiences of undertaking mixed method work in practice to be compared and contrasted. The work resulted in a number of lessons for mixed 
method work and highlighted opportunities for future work. However, a limitation of this work was the restricted information available in the published case studies. Therefore, an opportunity for further work was highlighted - namely the need to carry out in-depth evaluations of mixed method case studies to gain further understanding and lessons for the mixed method OR/MS community. The aim of this paper is to carry out such an in-depth evaluation, an aim that finds resonance in the various calls for researchers to undertake empirical studies determining how methods can be combined and conducted in practice (Small and Wainwright, 2014).

When considering how to approach an evaluation of mixed method OR work, recent work by Midgley et al (2013) provides some guidance through a framework developed for evaluating systemic Problem Structuring Methods (PSMs). Although this is focussed on PSMs, it is "based in the tradition of multi-method systemic interventions" (pp145-146). This framework includes four themes for evaluation; Context, Purpose, Methods, Outcomes. These four themes are not new, as Midgeley et al refer to a number of other researchers who propose similar frameworks that include some, if not all, of these themes. Another relevant, and recently published, set of criteria for evaluating case studies is presented by Ormerod (2014a). He promotes the use of the concept of the 'mangle of practice' (Pickering, 1995) to evaluate OR projects. It is suggested that the use of this concept encourages those evaluating a project to consider how different elements of the project (material, human and conceptual) interact over time with the aim of helping make better sense of what occurred. Ormerod (2014a, pp. 1246) states that the approach provides a "way of thinking about and describing some of the key motivating factors in an intervention, factors that affect the choice of issues to be addressed, the technical approach pursued and the success or otherwise of the final outcome". Each of these four areas are easily mapped onto Midgeley et al's four themes as follows:

- Key motivating factors: Context

- Factors that affect the choice of issues to be addressed: Purpose

- Technical approach pursued: Method

- Success of otherwise of the final outcome: Outcome

Furthermore, these areas/themes don't act in isolation. Method is informed by Context, motivating factors impact the choice of issues, success is determined by the issues etc. As such it is important to recognise the interactive element when considering projects as well as each element on its own. Ormerod (2014a) reviews a number of technical case studies in the literature and concludes that few explain the process of the intervention. Consequently, he highlights a number of criteria which an evaluation of a case study should consider. It is worth noting that, in addition to covering the themes already mentioned, one criterion highlights the need for a discussion regarding the role of the authors and actors. This is similar to Midgeley et al (2013) who particularly highlight the need to consider the researchers' role during all four themes.

When considering the specific situation of evaluating mixed method interventions, Howick and Ackermann (2011) explore a number of published mixed method interventions using five emergent themes. These themes are; (i) the nature of the modelling intervention (Purpose \& Context), (ii) how methods have been mixed together (Methods), (iii) the rationale given for mixing methods (Methods), (iv) the use of multiple facilitators/modellers (Modelling team) and ( $v$ ) client value (Outcome). Howick \& Ackermann's themes are consistent with the themes already discussed from 
the literature, with a key difference being that they are written focussed on the specific situation of mixing methods. As with Ormerod's and Midgeley et al's criteria, the role of the researchers and other actors is also of importance to this set of criteria. The 'Modelling team' theme provides consideration to the researchers and, as will be seen from the evaluation below, the role of the client and other key stakeholders, is a key consideration throughout the evaluation of all themes.

As Howick and Ackermann's criteria specifically emerged from the analysis of mixed method OR/MS work, and due to its consistency with other published themes used for evaluation purposes, this set of themes will be used to guide the analysis undertaken in this paper. Based on a rich set of gathered data, this paper will consider a mixed method intervention with respect to each of these themes in addition to highlighting any lessons learnt.

The next section will provide a background to the mixed method intervention and highlight the context in which the modelling takes place. As noted above, this is an important aspect of understanding how the case evolved. Sources of research data are then discussed before exploring the intervention with respect to each of the mixed method themes. A summary of the key learning points gained from the evaluation is presented before discussing the implications of the work and directions for future work.

Before proceeding with a description of the case, it should be noted that the authors will use the term 'mixing methods' throughout this paper. Although multi-methodology has been given particular attention in the OR literature (for example Mingers and Brocklesby, 1997; Jackson, 1999; Mingers, 2000; Mingers, 2003; Pollack, 2009; Zhu, 2011), in order to be inclusive, this paper will use the term mixed methods to represent the experiences of mixing OR tools, techniques, methods, methodologies and/or paradigms within a single intervention (Howick and Ackermann, 2011). The mixing that occurred during the project described in this paper includes both qualitative and quantitative methods. However, it is recognised that 'mixed methods' could involve bringing together entire methods or elements of multiple quantitative or multiple qualitative methods and need not necessarily bridge the qualitative/quantitative divide.

\section{The Case}

Scottish Hydro Electric Power Distribution (SHEPD) are the most northerly UK electricity distribution network operator with responsibility for the Shetland Islands, a small group of islands at the northern end of Scotland. The Shetland Islands are not connected to the UK electricity network and this infrastructure restriction limits the full integration of the renewable potential. Currently the majority of energy to the Shetland Islands is supplied by the Lerwick power station which is nearing the end of its operational life. The Lerwick power station is owned by Scottish and Southern Energy (SSE) Generation and operated by SHEPD. The UK regulator, Ofgem, gave approval in the form of a licence obligation to SHEPD to develop an integrated plan to manage the future energy supply and demand in the Shetland Islands in light of information gained from a project called the Northern Isles New Energy Solutions (NINES). The regulator recognised that the Shetland Islands context provided a unique opportunity to examine a new energy system designed to decarbonise supply. The NINES project had two phases. The first phase aimed to implement a smart grid to actively manage demand, generation and reactive compensation, to trial energy storage assets and demand side management, and to coordinate all these elements to maximise renewable generation capacity while maintaining supply quality and security. The second phase aimed to formulate a plan for the 
future energy system, especially addressing the need to upgrade or replace the Lerwick power station, in light of the learning gained and through relevant extension of the technologies used during the first phase. For more details on the NINES project, see

http://www.ninessmartgrid.co.uk/.

SHEPD invited academics with competences in electrical/power engineering, economics and management science to be involved in the NINES project. The project involved a number of work packages and the authors of this paper were responsible for a work package which focussed on risk identification and quantification. The objective of this work package was to identify, structure, quantify and work through the implications of risks pertaining to the NINES project taking note of the wider environment as seen by key stakeholders.

The approach adopted by the modelling team included both qualitative and quantitative modelling. The qualitative modelling involved running a series of risk workshops with participants from the NINES team (University researchers and energy company project managers), Shetland islanders (including councillors, wind farm owners, etc.) and technical members from SHEPD. Four risk mapping workshops were held, one each with the NINES team and Shetland Islanders and two with the SHEPD team. The second SHEPD team workshop took place 13 months after the first so that the changing nature of risks on the project could be assessed. Each workshop focussed upon eliciting a comprehensive set of risks, identifying their impacts upon one another and prioritising risk areas (Ackermann et al, 2014). Each risk identification and prioritisation workshop involved between 8 and 16 people ensuring a wide range of perspectives were incorporated. Participants were encouraged to consider a wide range of risks, with a typical focal question being "what are the risks (and opportunities) affecting the development of a successful energy system design that meets the foreseeable needs of Shetland". Risk maps were created which captured the participants' perceptions of key risks that the NINES project faced and how these risks impacted one another. From these maps, key risks themes were identified and prioritised to support the client in their allocation of resources. Further details regarding the risk workshops can be found in Ackermann et al (2014).

To ensure that insights gained during the workshops were transferred to the quantitative modelling stage, a member of the quantitative modelling team attended three of the workshops. Some of the insights gained were contextual in nature i.e. appreciating the political and social considerations; others were more specific for example, recognition of the risk of having skilled staff in place to manage the resultant solution. It should be noted that although the labels 'quantitative' and 'qualitative' modelling teams are used for convenience in this paper, each sub-team uses both forms of analysis. For example, the quantitative modelling team built the decision tree grounded in qualitative analysis and the qualitative team undertook quantitative risk prioritisation.

The risk quantification stage as implemented involved building a decision tree model that sought to support SHEPD in thinking through the generation options with respect to the capacity, size, design and location of a new conventional power plant given the uncertainties about the technologies, stakeholder actions and the wider political environment (Walls et al, 2013). Many of the uncertainties were identified during the risk workshops and developed into measurable variables during interviews with managers from SHEPD. Quantification of these uncertainties included the use of structured judgment elicitation methods (Bedford et al, 2007) to support a small number of 
SHEPD experts in expressing their uncertainties as probabilities. In addition, key uncertainties and additional data requirements to support the building of the decision tree were explored during the fourth risk workshop.

During the project, there were a number of challenges that had a significant impact on the progress of the work and contributed to its unfolding dynamics (Ormerod, 2014a). This fluctuating state of play is not unusual in large state of the art projects where there are a range of stakeholders. Due to their impact, the events are referred to throughout the paper and therefore a description of each of them follows:

(i) Uncertainty in the project

In its early stages, the NINES project experienced significant uncertainty over the scope, objectives and timeframe. This was due to a number of reasons. Probably most significantly, this project was the first of its kind for the organization where the client team needed to work with a range of key stakeholders all with their own objectives, competences and resources (particularly noteworthy were interactions with the regulator for whom the project type was also new). There were also uncertainties relating to the activities being undertaken by the different work packages. There was the need to be appreciative of insights and data emerging from the other work packages and also developments and activities undertaken by external key stakeholders - stakeholder management was a critical part of the entire NINES project. As a consequence, the scope was not fully understood at the outset either by the researchers or the client. The risk work package therefore required to be adaptable due to the uncertainties surrounding the project, which limited the level of detail that could be included in planned activities.

(ii) Client's project manager changed during the project

Half-way through the project, the client's project manager was pulled onto another project. His remit had been to manage the initial development of the NINES project. However, as the project became more focussed on the replacement of the power station, his skills were seen to be of more value to another project in the organisation. A replacement project manager was therefore brought onto the project to lead on the second phase of the project. The handover occurred during the early stages of building the decision tree.

(iii) Changes in purpose of the quantitative risk model

The original research intention of the quantitative modelling was to analyse the risk associated with the integration of the technologies being trialled in phase 1 given the recognised uncertainties of new energy systems not only by key NINES project stakeholders but also more generally (NERC, 2010). However as the project progressed, the focus of the quantitative risk model shifted to support phase 2 since it was clear to the modellers that conventional generation capacity would be required to replace the aging Lerwick power station and the client was interested in examining design options. A risk informed decision model was regarded as a means of appropriately representing 
and valuing options available to SHEPD in light of the uncertainties captured in the risk workshops. Further, a decision model would also draw on data in the form of state of knowledge assessments about the technology innovations being trialled in phase 1 as well as capturing the insights accumulated about the dynamic business environment in which the energy system was to be built and operated. Since the use of a decision tree had not been envisaged in the initial design of the risk work package there were implications for the integration of the two modelling approaches.

(iv) Modelling team had not previously worked together on a project

The team of modellers supporting the risk work package (who are the authors of this paper) included one modeller with an engineering background plus four modellers with differing, but extensive, experiences in risk modelling. Two of the risk modellers were experienced in running risk workshops together whilst the other two were experienced in jointly conducting probabilistic risk analysis. The engineer (Houghton) was involved in supporting all stages of the risk work package whilst two of the risk modellers were primarily involved in running the risk workshops (Ackermann and Howick: qualitative modelling team) and the other two risk modellers worked predominantly on the decision tree (Walls and Quigley: quantitative modelling team). Although both subteams had read a number of papers produced by the other pair, and had had informal discussions relating to the two methods and the attractiveness of integrating the approaches, there was no detailed consideration of the content integration or process demands (Eden, 1990). Whilst each modelling team had their own 'scripts' of how to operate (Ackermann et al, 2011) there was no exploration of how these might be brought together to form macro scripts. This had an impact on the integration of the two modelling stages and the presentation of these to the client. This, as noted below, would prove to be problematic.

The above describes some of the challenges that impacted the progress of the risk work package. As these form part of the 'Context' of the project, they can be considered alongside the evaluation criteria and will be referred to whilst reflecting on each of the mixed method themes.

\section{Case Evaluation using Mixed Method Themes}

Research data was generated from a variety of sources enabling triangulation (Denzin, 1978) to occur. During the workshops, members of the academic team acted as observers, taking detailed notes of the process and recording the participants' comments partly to ensure that insights gained from the workshops could be fed into the second phase of the project (content and modelling oriented) and partly to learn from the process of adopting and integrating the approaches (research and process oriented). In the spirit of Action Research (Eden and Huxham, 2006) detailed design notes were developed in advance of the workshop providing the basis for comparison between intended and realised activity (Ackermann et al, 2011). Alongside the researcher based notes, there was rich data available from the models created during the workshops and the analysis of this material (Eden et al, 1992). In addition, the software used to support the facilitation of the 
workshops kept detailed records - a second by second log - of the material being captured including who generated the material, number of times it was amended etc. The researchers' also kept detailed notes during the development of the decision tree including recording conversations with staff from SHEPD who were involved in the construction of the decision tree. Interviews were also carried out with 17 participants following the workshops and 2 NINES project managers from SHEPD who had participated in both stages of the modelling process. These final 2 interviews specifically focussed on understanding the client viewpoints with respect to the modelling approach adopted by the researchers'. The areas of discussion covered in these two interviews are shown in Appendix 1.

This data was examined using the 5 themes identified by Howick and Ackermann (2011) based on their review of the mixed method literature. As noted in section 1, these themes comprised: (i) nature of the modelling intervention, (ii) how the methods have been mixed, (iii) rationale for mixing methods, (iv) the use of multiple facilitators/modellers, (v) client value. For each of the themes, each data set was trawled identifying potential contributions/explanations for the particular theme (a form of content analysis using a priori codes (Miles and Huberman, 1994)). The Decision Explorer software was used to structure the contributions and consider how they related to one another. An example of an extract from the model that was built during the evaluation process is included in Appendix 2. Once this activity was completed, the data was reviewed to determine whether anything had been missed (i.e. were the themes comprehensive) and also whether the themes were sufficiently populated to stand on their own. This process was supported through clustering the contributions contained in each of the themes to highlight emergent sub-themes within each of the main themes. Whilst the themes appeared to have captured the key points emanating from the data sets, the themes of 'rationale for mixing methods' and 'how the methods have been mixed' appeared to contain much of the same material suggesting that these were not individual themes. It was decided that these should be combined under a single theme representing the 'Design and Implementation of the Intervention'. In addition, it was felt that the 'nature of the modelling intervention' theme resulted in context information that mainly led to lessons arising in one of the other themes. Three themes were therefore used to structure the evaluation; Design and Implementation of the Intervention, Modelling team - use of multiple modellers/facilitators and Client value.

The clusters of contributions were reconsidered based on the revised set of 3 main themes. The new sub-themes that emerged from these clusters provided the basis for a series of learning points with respect to mixing OR/MS methods. These learning points will be considered below under each of the three themes. Following consideration of each of the themes, a table will be presented that synthesises the learning points.

\subsection{Design and Implementation of the Intervention}

\section{(i) Lack of detail in mixed method design}

Prior to this project, the modelling team had frequently discussed the possible integration of their established risk modelling approaches and when invited to tender for the project they saw this as an ideal opportunity to combine their approaches. When putting together the tender the team agreed upon a design reflecting an integrated process where the two approaches informed one another 
over time (Bennett, 1985; Schultz \& Hatch, 1996; Mingers and Brocklesby, 1997; Morgan et al, 2015) and was expected to lead to a new method (Bennett, 1985). This process is also referred to as multimethodology when bringing together partitioned methodologies (Mingers and Brocklesby, 1997). This is in contrast to other types of mixing such as improving a method by taking on board elements of another method (akin to enrichment (Bennett, 1985) and enhancement (Mingers and Brocklesby, 1997)). Such an integrated design was of great interest to all of the team as they were keen to determine what benefits could be gained from the combination of the two different modelling approaches, recognising the limitations of each (Mingers and Brocklesby, 1997; Jackson, 1999; Mingers, 2000; Mingers, 2003). Similar to a multi-methodology design process (Mingers, 1997; Ormerod, 2014b), the approach recognised the complex and multi-dimensional issue being tackled and the need to consider the benefits and limitations of the methods to be used. With respect to the limitations of the methods, the qualitative modelling team were aware that whilst risk workshops had provided powerful insights, often decision makers sought to extend the insights through developing a more precise and defined set of actions. Likewise the quantitative team were aware that there was a danger that the modelling focused too quickly on a defined set of parameters and a more holistic overview recognising context would add value. However, the modellers desire to bring together their chosen approaches meant that a fuller consideration of all possible method combinations was not undertaken as may be appropriate in a multi-methodology design process.

However, whilst this desire to integrate approaches was jointly valued, there was little discussion regarding the details of the integration of the approaches - that is how the approaches would inform each other. This lack of detail was due to a general uncertainty around the project and a lack of detailed consideration of the content integration by the modelling team as mentioned in section 2 . The modelling team felt it was better to keep their options open, allowing a degree of flexibility to be retained to take into account any changes or developments.

Whilst, at the time, the designed in flexibility was perceived as an effective way of working, on reflection, there is a sense that it was not optimal. For example, it did allow some freedom when putting together a proposal of work to allow for changes in the project. However there were a number of ramifications. From the client's perspective the lack of detail prevented them from getting a good understanding of the different modelling approaches and their contributions. This had implications in terms of support and buy in. In particular this was highlighted in the post project interviews, when the clients noted that their lack of familiarity regarding the approaches initially inhibited their perception of their usefulness. For example, the first lead client noted "he was sceptical but open minded" about the workshops but once he had been involved in one workshop he saw the value. More detail in the beginning of the project would have helped resolve, at least to some extent, this problem (a factor relevant to all projects but particularly noteworthy when working with multiple methods as there are two or more methods to contend with). Once the client became more confident in the individual approaches, the lack of detail in the design also meant that the client was unsure how the separate approaches informed one another and added value. It was noted that this had an effect on client engagement as the client was unable to take on board the overall process and instead saw the two modelling approaches as valuable but discrete. It is also possible that the client's interest was determined by his role which involved working on new, and innovative projects and thus was attracted to one method more than the other. The second client came from a different part of the organization and therefore was familiar with a different set of norms and behaviours and thus had different views over modelling support. This illustrates 
Pickering's (1995) Mangle of Practice notion as not only did each client have a different conceptual mind set but had also different goals/objectives. As noted above, the project experienced a number of challenges and these exogenous events (forced on the project) reflected instances of "the temporal emergence of plans and goals and their transformability in encounters with material agency" (White et al 2015).

In addition, the change mid-way in lead clients resulted in each client experiencing a different modelling approach and as a result neither experienced the whole integrated approach. One of the clients noted that it would have been good to have a graphical representation of the two approaches detailing how one was informed by the other.

Having a more detailed design, one which could have subsequently been adapted if needed, would also have allowed the modelling team to gain a better understanding not only of the a priori considerations but also the reasons behind necessary changes and thus a more nuanced understanding of modelling in this complex environment. This detailed weaving together is particularly important where two methods need to be understood and appreciated in isolation as well as in combination.

Learning Point 1: Although others have reported successful mixed methods work that has involved evolving, and thus flexible, mixed method design (for example Kotidias \& Mingers 2006), in hindsight the lack of clarity in the integration of the two approaches impacted the NINES project (although each aspect clearly provided value to the client judging from comments from both clients). It inhibited learning in detail through not having a useful reference point against which the rationale for changes and their impacts could be reflected upon. It also almost certainly reduced the integration possibilities as the different options for sharing data and process were not fully articulated. Whilst flexibility is good, so too is being really clear about how each of the approaches are to inform and be informed by the other and how each stage of the process addresses client requirements.

Learning Point 2: Not only does detail in the design provide clarity for the modellers, but it also allows the process to be clearly communicated to the client, supporting buy in and allowing the client to communicate the process within their own organisation.

Learning Point 3: Ensuring that the client appreciates the value of both modelling approaches and in particular how using two approaches together improves the outcomes will further strengthen buy in. It is also likely to help in gaining time with clients thus facilitating the development of a good relationship and good communication flows. This could be achieved through either providing 'tasters' in the form of a mini workshop, a small decision tree etc. It might also be in the form of a graphic explicating both individual approaches and their interaction.

\section{(ii) Change of Client}

A change of project manager is not uncommon in projects as the project moves from the development phase to the execution phase but this nevertheless had an impact on the smooth running of the project (Parker and Skitmore, 2005). The switch inevitably involves some shift of emphasis. 
The remit of the first lead client project was to manage the initial phase of the NINES project (including attending to different stakeholder demands) and he was therefore involved in the design of the risk workshops and had subsequently commented on the value of the risk workshops. The second lead client led the second phase of the project focussing on the plan for the new energy system. Whilst he was involved as a participant in two of the risk workshops, he worked more intensively with the quantitative modelling team seeing real benefit in the decision tree and its contribution to cost benefit considerations as this fitted better his particular job role. This shift in project emphasis reflected both a changing focus of the project overall, as the project moved into a new phase, as well as different client's interests and style. The first lead client's remit was to work with enhancing overall understanding and developing a good mental model (Weick, 1995) of the risks facing the project. He therefore had an interest in the wider stakeholder and 'big picture' issues. The second lead client sought more explicit and tangible benefits. This shift may also be a reflection of the stage of the project and, as noted in (ii) above, the needs of the ultimate client, the regulator.

Learning Point 4: There is a need to be aware of the impact a change in lead client can have as this will not only potentially impact the project's objectives but also the style of interaction and will demand that time is expended building a good relationship with the new client. If the change in client occurs at the same time as a change in modelling approach (as it did in this project), this may hinder achieving an integrated process between the two methods and their acceptance.

Learning Point 5: When using combinations of methods, be sensitive to client preferences (Eden and Ackermann, 2004). Some clients will be more familiar and comfortable with qualitative methods, others less so. In some cases, qualitative modelling benefits may not be recognised as adding value as they are perceived to be 'soft' and imprecise (Ackermann, 2012). It is beneficial to ensure the client is appreciative of both. A client's preference may also be down to the individual roles of the clients and/or culture of their organization (or parts of it) and its level of comfort with different forms of modelling.

\subsection{Modelling team - Use of multiple facilitators/modellers}

\section{(i) Different modelling approaches}

As noted previously, the modelling team had not worked on a project together before and had not given detailed consideration to the required content integration or process demands (Eden, 1990). Thus both modelling teams held a number of assumptions about both process considerations and actual data/information exchange. Whilst each modelling team had their own 'scripts' of how to operate (Ackermann et al, 2011) there was no exploration of how these might be brought together to form macro scripts. This was exacerbated by the fact that the risk work package was only one part of the overall NINES project which was experiencing integration issues between the other work packages.

In addition to the modelling integration assumptions held by both modelling teams there were also facilitation assumptions, comprising details regarding the processes used when working with the client teams. Facilitation styles are idiosyncratic and although there are a number of well established 
guidelines (Bostrom, 1993; Phillips and Phillips, 1993) for good practice, how these are used, how the members of the team share the process and content management demands etc. vary. The qualitative modelling approach, stemming from a problem structuring origin, was adaptive and contingent recognising the need to adjust to changing organizational demands and shifting contexts. In contrast the quantitative modelling approach demanded a more focused design enabling the elicitation of focused, precise and refined data capture. These different data demands correlate with the need to balance ambiguity (to allow for the generation of uncertainty - both of the risks being elicited but also the relationships between the risks) with precision (Eden et al, 2008) as well as personal styles when operating with client teams. Neither team were deeply familiar with the technical language of the other, and whilst having this might have helped in the synthesis of the two approaches within the modelling team, there was a risk that the use of this language would alienate the client and thus would need to be managed carefully.

Learning Point 6: It is important to have a good appreciation of not just modelling approaches in terms of their requirements but also the intervention style of the modelling teams. Due to differences in style, the modelling team ended up working in two pairs rather than as a quartet. This was partly exacerbated by time pressure and competing demands on client time, which limited the time that could be spent considering how the separate teams 'scripts' could be integrated in a meaningful and useful way to produce a macro script to support the integrated approach.

One way in which each team can gain a good understanding of the other team's approach is to include some shared involvement in each other's activities. During the project one member of the quantitative team attended, as an observer, three of the risk mapping workshops. It has been noted that involvement in such workshops is where much of the learning occurs as there are limitations in communicating the outputs from discussions and the learning gained (Ackermann et al, 2014). When it came to development of the quantitative model there was limited involvement of the qualitative modelling team in the data gathering and model building. Thus an integrated modelling approach could seek for inclusion of members from each approach in the modelling efforts recognising time pressures. This would also help in the alignment of technical terms. This may also help support understanding of the modelling demands, benefits and styles of interaction. For example it would have been interesting to have both the quantitative modellers experience the qualitative workshops and for the qualitative modellers to attend the meetings capturing data from members of the client organisation. Further context information as well as design suggestions may have been identified.

Learning Point 7: Ensuring there is built in agreements for shared involvement could be beneficial when mixing methods, acknowledging that this will have time demands.

\section{(ii) The Impact of a change in the client's needs}

The original modelling intention was that the quantitative team would undertake a form of reliability modelling. However, engagement with the client highlighted that this method was no longer appropriate (it is worth noting that critical reflection on method choice is an important aspect of the implementation of multi-methodology (Ormerod, 2014b)). When it was realised that this did not best suit the client's needs at this stage of the project, this caused a number of confusions in the modelling integration as anticipated mechanisms for integration were no longer relevant and the 
modelling team had to determine which alternative approach to use and what integration might be possible.

Learning Point 8: Being au fait with each other's work is particularly significant if the scope of the project changes. If part of the team is working with the client, and a change is suggested to the remit, opportunities may not be capitalised upon if members of the team are unaware of the potential ramifications on the modelling. Thus the combination will not be as powerful. There needs to be clear and quick communications through the modelling team of any changes in client requirements so that any impacts on and opportunities for the modelling engagement can be quickly identified and adopted/adapted.

Learning Point 9: The change in design of the modelling intervention meant that the two modelling approaches were less aligned with one another. Although a mixed method design can be well planned, it is important to be adaptable to the needs of the client, but this can be challenging. When working with a single method, a change in design may mean that the modeller needs to learn a new method. However, when mixing methods the challenge is even greater as there may not only be implications for each of the methods, but also the manner in which they are able to integrate with one another, thus providing uncertainty over the plausibility and value of the whole modelling design. Thus, when changes occur, it is important that the modelling team works together to assess the impact of the change on the overall design to ensure the plausibility and value of the design going forward.

\section{(iii) Consultancy $v$ Research}

Although the project had been contracted as research, there seemed to be uncertainty as to the role of the research teams in the mind of the client. While the researchers saw themselves as providing support and tools that would enable the client to successfully implement the project, the client at times appeared to view the teams as consultants charged with providing a definitive set of 'answers'. This had implications for the nature of the discussions with the client and on the approach to reporting progress. This tension is one constantly faced by researchers undertaking action research based work. The researchers in this case had a clearly defined objective, and the research design was 'research qua intervention' rather than 'intervention qua research' ameliorating issues arising around the validity of action research and its relationship to consultancy (Eden and Huxham, 2006; Susman and Evered, 1978). However, during the project, the researchers found themselves moving towards the latter to support the client's needs. This highlighted the researcher/consultant role as a continuum where modellers have to be adaptable depending upon the state of the project. Getting the balance right in terms of the contribution of the research team also spills into the forms of support. For much of the qualitative OR world, this support concentrates on attention to process and content management (Eden 1990) however this has been extended to include varieties of 'substantial or expertise' contribution (Huxham and Cropper, 1994).

It appeared that the issue outlined above was less acute for some of the other university research teams particularly those working on the more defined and familiar technical considerations e.g. smart grids. Here the research being undertaken was better understood by the client who "spoke the same language" and could immediately relate to the complexities and activities and were familiar with the evolving research led nature of discovery. It was also in the form of technical or expertise advice rather than process and content management support. This greater level of 
familiarity also reinforced and was reinforced by the relationship that existed between the engineering teams and the client who had worked together on many occasions and whose engagements were mainly consultancy orientated. Past project were regularly referred to and many of the concepts discussed related to other projects experienced by both parties. On the other hand, the risk work package team had to develop a new relationship with the client, introduce them to new ways of thinking about their business and to develop an understanding of the clients' expectations for research and consultancy work.

In addition, the project had a tight timescale and thus there was a sense that there was limited time to work on the integration, both within the modelling work package and bringing all the work packages together. Thus opportunities potentially were missed. This lack of time also meant that further integration, both within the risk work package and across work packages, was not possible. Modellers were keen to understand how elements from the qualitative and quantitative modelling approaches could further support each other, for example through the integration of 'scripts'. However it was recognised that was a research agenda of more interest to the modellers than the client.

Learning Point 10: Modellers need to be sensitive to the basis by which they are being asked to embark on the project - is it as a consultant or as a researcher as this will have implications for the expected outcomes of the consultant/researcher and client. However, it is recognised that the choice between the two may not be clear cut and in some projects modellers may end up as part researcher and part consultant. Thus, the researcher/consultant roles can be viewed on a continuum where modellers need to be adaptable and may move along the continuum during a project as the project and the client's needs develop. It will be also be influenced by the culture of the organization and the expected norms.

\section{(iv) Single project manager}

Learning Point 11: In reflecting on the above set of learning points and other projects, a further learning point is the need for a single project manager for the modelling effort. On other projects the modellers have been involved in, particularly when involving a number of modellers and modelling techniques, those projects that had been particularly successful included a project manager for the modelling team who drove the process and had oversight to all of the techniques being used. In this project, the five researchers believed that they would work effectively as a collaborative. There was no lead possibly due to the fact that all of the team were equal in terms of their position in their own organization. It could be postulated that having someone to manage the project would have ensured more integration as they could dictate certain actions particularly when changes occur (Parker and Skitmore, 2005). However it is recognised that the success of using a single project manager in previous projects was partly founded on the project manager's good understanding of each of the team members modelling approaches.

\subsection{Client value}

Client value can be seen as an ephemeral quality as clients value different things at different times depending on circumstances. Clients, particularly busy senior managers, will be juggling a range of 
issues from the strategic to the urgent, and thus salience shifts. As mixed methods projects typically encompass a period of time, the focus of the client shifts, as is evidenced in this situation, thus changing what is valued. Consequently, one way of understanding client value is to consider their 'pain' (Eden and Ackermann, 2004) and address that, recognising the issue of concern will change over time. Thus, as the modelling helps resolve one issue priorities shift to another. Flexibility is therefore important when considering client value, and using different methods in combination adds to the OR modeller's ability to provide value.

Although client value is of great importance to a modeller it is thinly addressed in published cases on mixing methods (Small and Wainwright, 2014) with little evaluation undertaken post-intervention, although Ormerod (1996) is an exception. However, when client value is addressed, there is little distinction made between the value of the individual methods and the contribution of the combined approach (Howick and Ackermann, 2011). The first two parts of this section therefore seek to consider this distinction by considering both the learning from the individual methods used and the learning resulting from the mixing process.

\section{(i) Client value from individual methods}

As previously noted, this was a new type of project for the client to undertake. It was one that involved a wide range of stakeholders and a greater reliance on other parties to deliver aspects of the project than the client were familiar with as well as being state of the art in terms of technology. The client had to therefore engage more extensively than hitherto with these parties and their working cultures, objectives and concerns. For this reason the client recognised that the project needed to take a different approach to those used for previous projects. Thus, if client value was to be gained, the adopted approach needed to attend to the clients' objectives which included; the involvement of stakeholders, meeting the regulator's requirements, a clear consideration of the costs and benefits associated with the available options for repowering Shetland and ensuring that the 'lights were always on'. It was also recognised that the above objectives were likely to be key considerations for future projects which the client would be involved in (as the requirements being demanded by the regulator were emerging as a new trend in the industry) and thus value could also be gained in introducing the client to approaches that could be used beyond the specific project so that they could be adopted in future projects. Learning from the project was a key consideration and formed part of one of the work packages within the project. The two modelling methods chosen fitted with both of the immediate objectives of engaging a wide variety of stakeholders and ensuring detailed cost/benefit analysis would be undertaken and alerting the client to potential methods for supporting future project decision making.

Seventeen participants were interviewed following the risk workshops. These interviews were carried out by the qualitative modelling team and the structure of the questions was based on the themes that emerged from the review of mixed method modelling work carried out by Howick and Ackermann (2011). A number of benefits were highlighted with the workshops clearly providing value to the organisation (directly and indirectly). Participants reported that the benefits included; being a comprehensive approach to risk assessment, capturing the interaction between risks, being inclusive, providing a holistic picture and being an improvement on traditional methods (further discussion of these benefits can be found in Ackermann et al, 2014). In addition, the client reported 
that the output of this work had impacted which risks they included in their risk assessment process, including those that were reported to the regulator.

Interestingly, the value of the workshops was seen differently by the different project managers reflecting that value is dependent on the client's involvement, priorities and interests (Eden and Ackermann, 2004). The initial project manager reported that the value of the workshops had been recognised in SHEPD and believed that the workshops will have an impact on how the organisation thinks about future risk processes. In particular, he highlighted the benefits gained in bringing together "a wider range of perspectives" with a "blend of broader views". However, when asked to provide examples of the impact of the workshops on the day to day risk assessment, the second project manager found this difficult to answer. His belief was that, subconsciously, people may have changed their behaviour, but it was difficult to say what specific actions were impacted as it was impossible to know what would have happened if the workshops had not been carried out.

Learning Point 12: This highlights a general difficulty with many forms of OR/MS modelling. The impact, and thus value, of the modelling process can be difficult to assess as it is being tested in a real case, rather than being assessed in a laboratory environment, where it could be compared to a control group (Eden, 1995). Thus, proxy measures for the value of the work may need to be sought, for example the client wishing to use the method again in future work.

Re-iterating the earlier point about different perceptions of value, the second project manager felt that the decision tree work was "a critical piece of work to the overall project". It had a significant input into the cost/benefit analysis required by the regulator. In addition to the output of the model being of use, the project manager also commented that the model building process was of value to those involved as "the questions stimulated a different thought process and a different level of discussion", providing those involved with "ideas for avenues to explore in more detail".

Learning Point 13: The client's comments highlight that involvement in the modelling process is key to enhancing a stakeholder's understanding. This is widely recognised in the OR/MS field particularly when developing 'soft' OR/MS model (for example Checkland and Poulter 2010, Ackermann and Eden 2010, Rosenhead and Mingers 2001). However, the benefits highlighted by the client arose from involvement in developing a quantitative model highlighting the significance of the quantitative approach beyond the objective of providing a cost/benefit analysis. The process of developing the quantitative model provided a structured enquiry that provided valuable insights into the problem area (Howick and Eden, 2011).

\section{(ii) Client value from mixing methods}

The above suggests that there was clear client value from participation in both the risk workshops and the construction of the decision tree. However, was there any added value from bringing the two methods together? This is a particularly pertinent question to ask as the modelling team were concerned about the limited integration that took place between the two methods during the project.

Both project managers were asked what value, if any, they believed was gained from using the two methods together. The second project manager believed that in order to facilitate the building of the decision tree, the risk elicitation process provided the facilitators with sufficient knowledge of the 
project. The modellers agreed with this view as modelling as a sequential process meant that the workshops provided the risk landscape to inform the modelling of the uncertainties in the decision tree. Value may also be gained as use of the first method provides an opportunity to build client confidence in the modelling team and their work. Relationships can be developed at this stage, so that when moving to using the second method, this 'hurdle' has been overcome. This may also lead to earlier stages having a positive impact on communication and insights in the later stages (Franco and Lord, 2011). However, it is noted that, in this project, different modellers led the two stages in addition to there being 2 different clients. The initial project manager reported that the "disjoint between the two stages" was the part of the project where he felt most disappointed.

Overall, the clients confirmed the value they believe they have gained from the individual methods stating that they will use the decision tree process again in future projects and have already used risk workshops on subsequent projects. However, the client has not indicated an intention to use these methods together. This may demonstrate a lack of perceived value in the mixing of the methods. However, it could equally be that there are no immediate purposes within the organisation for the use of both methods. In addition, it may be that the client perceives benefits with individual methods and would happily use each again as required, but would not necessarily plan an integrated approach using multiple methods.

Learning Point 14: On reflection, there may be a number of reasons for the lack of perceived value of the integration process; the lack of attention to designing the integration of the methods, the lack of consistency in the modelling team when moving between different methods, the change in client, or the client not believing future projects would require the same combination of methods. Each of these, bar the last, highlight areas where attention is required if it is deemed necessary that the client should understand the value from the combined modelling process. This would help highlight the benefits in the literature with respect to the use of mixing methods (Mingers, 2000).

\section{(iii) Different audiences engage with different models}

Although each project manager did not perceive significant value from the overall integrative process, it was observed that the different project managers engaged with different parts of the process. It was evident that the initial project manager appreciated the value of the risk workshops, whereas the second project manager was particularly engaged with the decision tree modelling. This has been noted in previous combinations (Howick et al, 2008) where the combination of methods is well understood by the client and has been demonstrated to yield added value through being an integrated set of approaches, but where different stakeholders take benefits from different aspects of the overall project.

Learning Point 15: It is important to recognise that not everyone will appreciate all of the aspects of the modelling approach but that the combination is required so as to provide the suite of benefits. Likewise different parts of an organization and different organizations may view the integration of methods more or less positively depending on their values and culture (Mingers and Brocklesby 1997).

\section{4: Summary of Learning Points}


To conclude, the aim of this paper was to carry out an in-depth evaluation of a mixed OR method case study. This case study involved an intervention which formed part of a large state of the art energy project - the NINES project. The NINES project was a complex project, involving many stakeholders. The modellers faced a number of challenges throughout the intervention which impacted on the progress of the work and contributed to its unfolding dynamics. The case study is undoubtedly idiosyncratic in nature with the work involving a specific mix of modelling approaches and a specific modelling team. However, the authors anticipate that OR modellers who are experienced in mixing methods in practice will identify with, and be interested in, many of the issues and lessons that have been raised during the evaluation.

A summary of the learning points that have emerged from the evaluation is provided in table 1 below. This table summarises the learning points and considers their impact both with respect to a general OR modelling process in addition to the specific impact on a mixed method modelling process.

\begin{tabular}{|c|c|c|c|}
\hline & Learning Point & $\begin{array}{l}\text { Impact on General } \\
\text { Modelling Process }\end{array}$ & $\begin{array}{l}\text { Impact on Mixed } \\
\text { Method Process }\end{array}$ \\
\hline & \multicolumn{3}{|l|}{$\begin{array}{l}\text { Lack of detail in mixed methods } \\
\text { design }\end{array}$} \\
\hline LP1 & $\begin{array}{l}\text { Ensure a clear detailed plan is } \\
\text { produced explicating the } \\
\text { integrated modelling approach for } \\
\text { learning purposes }\end{array}$ & $\begin{array}{l}\text { To provide a } \\
\text { reference point for } \\
\text { reflection }\end{array}$ & $\begin{array}{l}\text { To articulate the } \\
\text { options for integration }\end{array}$ \\
\hline LP2\&3 & $\begin{array}{l}\text { Provide client with clear } \\
\text { explanation (and diagram) of the } \\
\text { integrated modelling approach } \\
\text { through demonstrations etc }\end{array}$ & Client buy-in & $\begin{array}{l}\text { Client appreciates value } \\
\text { of all methods working } \\
\text { in harmony }\end{array}$ \\
\hline \multicolumn{4}{|c|}{ Change of Client } \\
\hline LP4\&5 & $\begin{array}{l}\text { Be alert when project managers } \\
\text { change - both in terms of shifting } \\
\text { objectives but also foci }\end{array}$ & $\begin{array}{l}\text { New client to build } \\
\text { relationship with }\end{array}$ & $\begin{array}{l}\text { When mixing methods, } \\
\text { different client may } \\
\text { have different } \\
\text { modelling preferences }\end{array}$ \\
\hline \multicolumn{4}{|c|}{ Different modelling approaches } \\
\hline LP6 & $\begin{array}{l}\text { Explore the different intervention } \\
\text { styles used within the modelling } \\
\text { team }\end{array}$ & & $\begin{array}{l}\text { To enable individual } \\
\text { teams scripts to be } \\
\text { brought together to } \\
\text { produce useful macro } \\
\text { scripts for the } \\
\text { integrated approach }\end{array}$ \\
\hline LP7 & $\begin{array}{l}\text { Ensure there are built in } \\
\text { agreements for shared } \\
\text { involvement in the modelling } \\
\text { process }\end{array}$ & & $\begin{array}{l}\text { Greater understanding } \\
\text { of each part of the } \\
\text { modelling process } \\
\text { leading to an increased } \\
\text { opportunity to refine } \\
\text { the design of the } \\
\text { intervention }\end{array}$ \\
\hline
\end{tabular}




\begin{tabular}{|c|c|c|c|}
\hline \multicolumn{4}{|c|}{$\begin{array}{l}\text { Impact of a change in the client's } \\
\text { needs }\end{array}$} \\
\hline LP8 & $\begin{array}{l}\text { Clear communication of changes in } \\
\text { client requirements through the } \\
\text { modelling team }\end{array}$ & $\begin{array}{l}\text { Quick assessment } \\
\text { of impact and } \\
\text { opportunities for } \\
\text { the intervention }\end{array}$ & $\begin{array}{l}\text { Quick assessment of } \\
\text { impact and } \\
\text { opportunities for all } \\
\text { parts of the integrated } \\
\text { modelling approach }\end{array}$ \\
\hline LP9 & $\begin{array}{l}\text { Work together as a team when } \\
\text { identifying changes to original } \\
\text { design }\end{array}$ & & $\begin{array}{l}\text { Ensure plausibility and } \\
\text { value of the integrated } \\
\text { approach }\end{array}$ \\
\hline \multicolumn{4}{|c|}{ Consultancy v Research } \\
\hline LP10 & $\begin{array}{l}\text { Be alert to how the client perceives } \\
\text { the modeller's role i.e. consultant } \\
\text { or researcher }\end{array}$ & $\begin{array}{l}\text { Clarity and } \\
\text { agreement on } \\
\text { expected outcomes }\end{array}$ & \\
\hline \multicolumn{4}{|c|}{ Single project manager } \\
\hline LP11 & $\begin{array}{l}\text { Establish a single project manager } \\
\text { who has oversight of all } \\
\text { elements/approaches of the } \\
\text { modelling effort }\end{array}$ & & $\begin{array}{l}\text { Pay specific attention to } \\
\text { the integration process } \\
\text { and client appreciation } \\
\text { of integration }\end{array}$ \\
\hline \multicolumn{4}{|c|}{$\begin{array}{l}\text { Client value from individual } \\
\text { methods }\end{array}$} \\
\hline LP12 & $\begin{array}{l}\text { Proxy measures for the value of } \\
\text { client work may need to be sought }\end{array}$ & $\begin{array}{l}\text { Difficulties in } \\
\text { assessing the } \\
\text { impact of work }\end{array}$ & \\
\hline LP13 & $\begin{array}{l}\text { Quantitative modelling can play a } \\
\text { role in supporting problem } \\
\text { structuring as part of a structured } \\
\text { enquiry }\end{array}$ & $\begin{array}{l}\text { Benefits from } \\
\text { quantitative } \\
\text { modelling }\end{array}$ & $\begin{array}{l}\text { Considering the role } \\
\text { that quantitative } \\
\text { modelling can play } \\
\text { when integrating } \\
\text { methods }\end{array}$ \\
\hline \multicolumn{4}{|c|}{ Client value from mixing methods } \\
\hline LP14 & $\begin{array}{l}\text { Get client to understand the value } \\
\text { from the combined modelling } \\
\text { process }\end{array}$ & $\begin{array}{l}\text { Builds client } \\
\text { confidence in } \\
\text { models and } \\
\text { modellers }\end{array}$ & $\begin{array}{l}\text { Client considers future } \\
\text { work where integrated } \\
\text { process can be of use }\end{array}$ \\
\hline \multicolumn{4}{|c|}{$\begin{array}{l}\text { Different audiences engage with } \\
\text { different models }\end{array}$} \\
\hline LP15 & $\begin{array}{l}\text { Recognise different clients will take } \\
\text { different benefits from modelling } \\
\text { effort }\end{array}$ & & $\begin{array}{l}\text { Different audiences may } \\
\text { build confidence in the } \\
\text { process through } \\
\text { different parts of the } \\
\text { integrated approach }\end{array}$ \\
\hline
\end{tabular}

Table 1: Summary of learning points 
The learning points presented in table 1 cover a wide variety of modelling considerations, spanning both content orientated issues as well as process oriented insights and attend to both the role of the modeller and the client. By considering the impact of the learning points on both general OR modelling and mixed method OR/MS work, table 1 highlights that, in some cases, the impact is similar for both but it is exacerbated within the mixed method situation. That is, the difficulties that arise in a modelling intervention are amplified when multiple methods are being used. However, in other cases, the use of a mixed method approach provides new considerations. For example, in LP2\&3 client buy-in may require the client to understand more than each of the individual methods.

It is noted that some of the learning points can also help to provide practical lessons for conceptual design processes such as multi-methodology. For example:

- LP1: A detailed plan should take account of the process design for mixed methods

- LP7: There is a need for all modellers to appreciate one another's methods to ensure appropriate combinations are constructed to tackle an issue

- LP13: A recognition of the role that quantitative modelling can play in a mixed method design

This highlights further opportunities for how the conceptual and practical considerations of mixing methods can inform one another.

Although the learning points are presented as a list in table 1 , it is recognised that they are not independent of one another. For example, having a single project manager (LP11) may help support communication of changes in client requirement (LP8) and gaining agreements for shared involvement in the modelling team (LP7). Also, the level of detail of the integrated modelling approach (LP1) will impact any changes needed to the original design (LP9) and how individual modelling scripts are brought together (LP6). Modellers may therefore not wish to consider these points in isolation from one another, but consider portfolios of learning which they can take onto future projects. Thus taking a more systemic consideration may be necessary for comprehensive learning.

The authors have found the reflection process useful to consolidate the learning gained from this particular project and hope that other modellers find the learning points useful when engaging in future mixed method interventions - with the learning points forming a dialectic mechanism. The modelling effort as part of the NINES project was not unlike any other large modelling project - not all aspects of this project progressed as expected and parts of the process could have been improved upon. Moreover, learning can be far more pronounced when reflecting on an experience that was deemed not to be fully successful. To further develop this work, the authors would encourage the publication of evaluations of both successful and less successful case studies so that a repository of learning can be developed.

\section{Discussion and Future Work}

The evaluation carried out in this paper was guided by a set of themes that had emerged from previous work which sought to highlight lessons from a set of mixed method case studies. This set of themes was found to be consistent with other sets of themes proposed in the literature for the evaluation of OR modelling interventions. However, it is interesting to note that the authors in this 
paper did not include 'Context' as a separate theme in this work as it impacted many of the learning points arising from all the other themes. Context is pervasive and thus separating it potentially misses key insight. Systemic reflection and identification of learning points is likely to yield insights that are far more nuanced and apposite. The set of themes used also highlight specific areas that may be worthy of exploration when focussing on mixed method case studies. The proposed set of themes suggests that an area for specific consideration is the modelling team and how the different members of that team integrate as part of the mixed method modelling process. The learning points that emerged from the evaluation of the case study suggest that this is an area which requires specific attention when entering into a mixed method intervention.

Alongside the anticipated benefits to modellers, there is the issue of helping students gain confidence and competence in mixing OR methods if there is to be an increase in uptake. However, teaching students raises a number of problems. The first problem relates to the fact that in order to be able to effectively mix methods, students will need to gain competence in at least two methods. Howick \& Ackermann (2011) have highlighted the challenge for experienced modellers to be au fait with more than one method, particularly if the methods straddle the qualitative quantitative spectrum.

The second problem relates to the complexities of teaching Soft OR (Ackermann 2012; Ackermann 2015). Whilst gaining expertise in quantitative modelling demands a detailed understanding of the underpinning principles, and a recognition that complete data sets may not be available or have to be managed, it does not additionally require students to be able to facilitate groups interactively and contingently. The added burden of process management and the concomitant demand for an understanding of the socio-political demands of organizational life add extra demands (particularly when the student is studying at the undergraduate level and thus may have little to no experience of the corporate world).

The third and final problem builds on the previous two where students are expected not only to have the expertise in two methods but also to understand and appropriately take into consideration design processes for mixing methods. Whilst there are useful frameworks (Flood and Jackson, 1991) these provide little in the way of details - making actual implementation a challenging business.

Consequently innovative approaches to teaching effective mixing of methods to build competence are required. For the first problem, the breadth and depth of current teaching programs need to be considered to ensure competence in individual methods. For the second problem, the biggest issue many students have is the sense of insecurity - that there is not a single right way to proceed and thus the need for "thinking on your feet" (Ackermann, 2011) and seeking new forms of apprenticeship is a key way in developing relevant experience. For the third problem, the development of facilitation scripts may help support more effective mixing. There is a growing recognition of scripts for application (Andersen and Richardson 1997; Ackermann et al 2011) and those that seek to provide blueprints for combinations will be most helpful. Finally, as noted in earlier work (Howick and Ackermann, 2011) mixing methods is most likely to be team based (overcoming detailed expertise in each method) and thus identifying the key characteristics for successful team working need to be identified.

A further consideration is viewing the case study through the lens of Pickering's Mangle of Practice as recommended by Ormerod (2013) as this may provide further useful insights. For example when 
considering the design of the research project, existing practices were 'mangled' together to form a new whole (as reflected by the mixing of methods). However this 'mangling' was not sufficiently considered as noted by the above learning points relating to, for example, neither team being deeply familiar with the technical language of the other. Thus there were two conceptual mind sets seeking to use the project as a bridgehead but without sufficient consideration of how the different disciplines hung together.

Moreover the case through its state of the art nature and its involvement of a wide range of stakeholders would have benefited from some explicit mangling of material, human, conceptual and social relationships - as the risk researchers, other academics involved, players within the energy company and recipients of energy generation each had different preferences which collided at different points in time (and which were also impacted by external events). The research design would have benefited from a recognition of the need to attend to the dynamic intertwining of conceptual mind sets, goals, etc. As such, this would address the two risk modelling teams perspectives (both OR oriented but different in emphasis), the other academic conceptual mind sets (mechanical engineering, power engineering, economics), those of different SHEPD employees and consumers. Thus "each participant represents symbolically and in terms of actual knowledge, an aspect of the material world, which must be voiced to other workshops participants in order to not mislead the workshop.." where workshops could be the risk workshops, design workshops etc. Finally it is worth noting that the design needs to account for constant change, in much the same way as Adaptive Structuration Theory asserts the social impacting the technical and vice versa (Orlikwoski, 2000).

Working with mixing methods is challenging - but can be very rewarding - both for the modellers and the clients. This paper provides some insights into the use of integrated modelling approaches and where potential pitfalls may emerge. However there is more work to do.

It is not surprising that the client is a focus of many of the learning points listed above. However a question still remains over how much client value can be gained from the integration of multiple methods as compared to the benefits gained from using the individual methods. In addition to this there is the issue of helping the client appreciate from where the value has arisen (Ackermann, 2012). Further work attempting to pull apart where clients find value during a mixed method approach would be beneficial to inform future work (Small and Wainwright, 2014).

Working in teams can be a challenge and is an area for further reflection, particularly with respect to the integration of differing intervention styles. One of the learning points suggests the use of a single project manager when bringing multiple methods together. The authors have had experiences where a mixed method modelling team consisted of just 2 modellers and the need for a project manager was not deemed necessary. This begs a question regarding the conditions that are required for a project to benefit from such a project manager. Is it based upon a certain size of modelling team, or a certain type of client or when tackling certain types of client objectives? These are considerations for future work.

Consideration of the use of themes to guide the evaluation process resulted in only 3 themes being used. It is recognised that these themes only provided high level guidance. Future work could therefore consider whether more detailed criteria could be developed, which is specific to mixed method work, to further support the evaluation process. In addition, It is recognised that other lens 
exist through which a mixed method case study could be evaluated. Future work could consider how the themes in this paper could be enhanced through contributions from, for example, the Mangle of Practice (Ormerod 2014a) as mentioned above.

The introduction to this paper suggested that recognising and sharing generic lessons for mixed method OR work could prove beneficial to both practitioners and researchers. To help achieve this, the authors of this paper would encourage the development of a repository of learning taken from evaluations of both successful and less successful case studies. To support this, interviews with both clients and modelling teams would help gain understanding of how mixed method work has been undertaken in the past and the value that has been gained from it. By doing this, it is hoped that future mixed method modellers can learn from past interventions and thus can take advantage of these experiences when approaching a new mixed method modelling intervention.

\section{Acknowledgements}

The authors would like to acknowledge the support they received from Scottish Hydro Electric Power Distribution.

\section{Appendix 1}

The semi-structured interviews carried out with the two project managers focussed on the following areas:

- Before the modelling began, what were their expectations of the process

- Gather comments on the individual modelling methods and their use in supporting the project managers and their organisation

- Would the project managers and/or their organisation use the individual modelling methods again in the future (partly as a proxy to understand client value)

- Did the project managers see/understand the linkages between the two modelling methods

- Was there any perceived added value from both modelling methods working together

- How did this approach to risk assessment compare to the organisation's traditional approach? What was good/could be improved regarding the mixed method approach?

- Was there anything interesting/useful/surprising about the process?

\section{Appendix 2}

An extract from the Decision Explorer model that was constructed during the evaluation process 


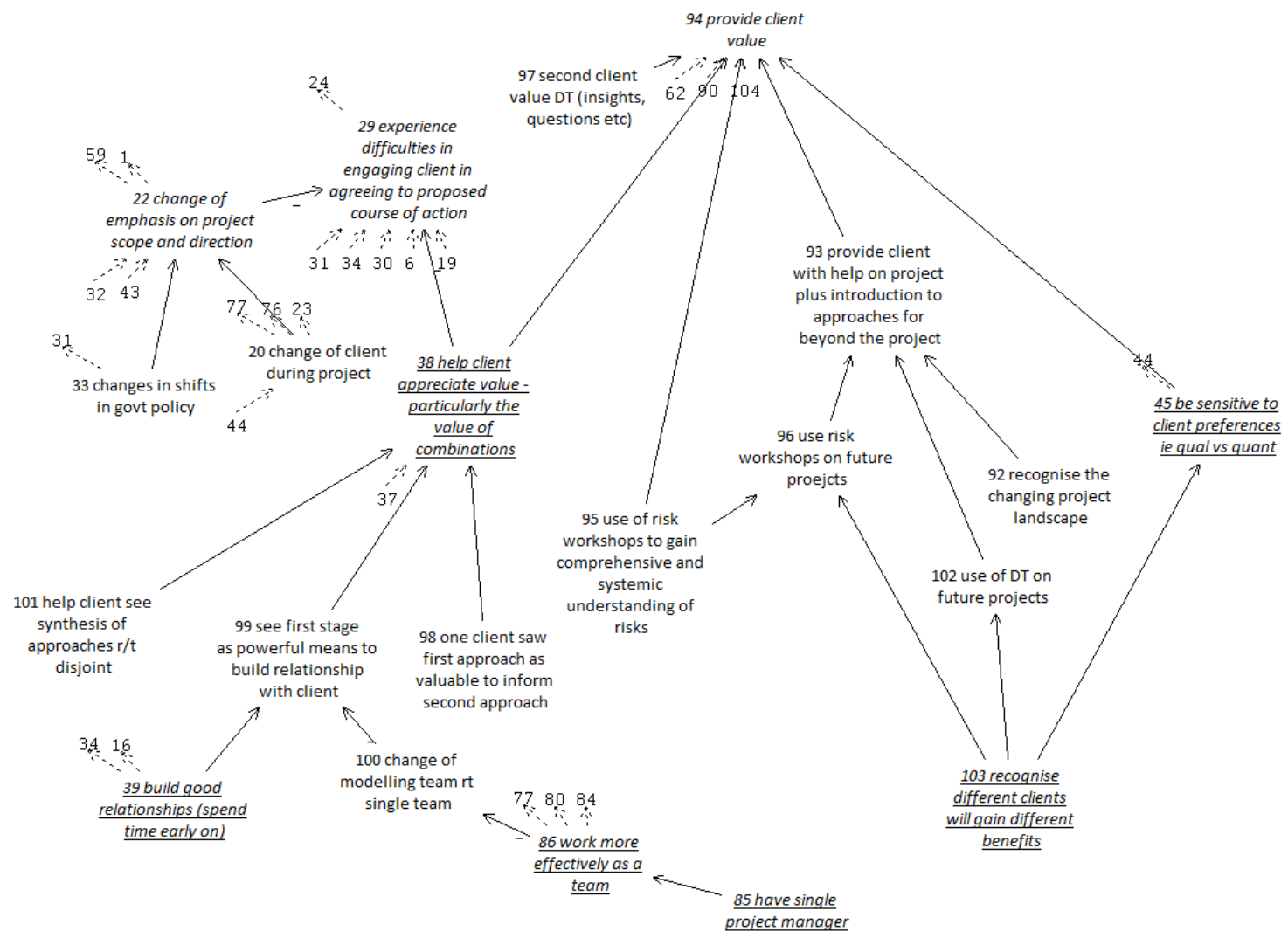

The numbers attached to the concepts are for reference only. The dotted arrows represent links to, or from, other concepts that are not shown on this extract. The arrows represent causality thus 85 have a single project manager may lead to 84 work more effectively as a team

The map brought together information gained from the various data sources described in the paper. The concepts that are italicised represent 'busy' concepts - those that have the most concepts linking in and out of them and thus are highly interconnected, suggesting key areas of interest. Concepts that are italicised and underlined are those identified as learning points.

\section{References}

Ackermann F (2011). 'Getting messy' with problems: The Challenges of Teaching 'Soft' OR. INFORMS Transactions on Education, 12, (1) 55-64.

Ackermann F (2012). Problem Structuring Methods 'in the dock': Arguing the case for Soft OR' European Journal of Operational Research; 219: 652-658.

Ackermann (2015). Teaching Soft OR/MS Methodologies: what, why, and how. In James Cochran (Ed.) Wiley Encyclopaedia of Operations Research and Management Science. Forthcoming. 
Ackermann F, Eden C (2010). Strategic Options Development and Analysis. In Reynolds M and Holwell S (Eds). Systems Approaches to Managing Change: A Practical Guide. London: Springer; 135190.

Ackermann F, Andersen, DF, Eden C and Richardson GR (2011). ScriptsMap: A tool for Designing Multi-Method Policy-Making Workshops, Omega, 39, (4) 427-434.

Ackermann F, Howick S, Quigley J, Walls L, Houghton T (2014). Systemic risk elicitation: Using causal maps to engage stakeholders and build a comprehensive view of risks. European Journal of Operational Research; 238(1) :290-299.

Andersen DF, Richardson GR (1997). Scripts for Group Model Building. System Dynamics Review 13(2): 107-129.

Bedford T, Quigley J and Walls L (2007). Expert Elicitation for Reliable System Design (with discussion) Statistical Science; 42: 428-462.

Bennett PG (1985). On linking approaches to Decision-Aiding: Issues and prospects. Journal of the Operational Research Society; 36(8): 659-669.

Bostrom BR, Anson, Clawson V (1993). Group Facilitation and Group Support Systems? In L. Jessup and J. Valacich (Eds.), Group Support Systems: New Perspectives. New York: Van Nostrand Reinhold.

Checkland P, Poulter J (2010). Soft Systems Methodology. In Reynolds M and Holwell S (Eds). Systems Approaches to Managing Change: A Practical Guide. London: Springer: 191-242.

Denzin NK (1978). Sociological Methods. New York: McGraw-Hill.

Eden C (1990). The Unfolding Nature of Group Decision Support - Two Dimensions of Skills. In C. Eden and J. Radford (Eds) Tackling Strategic Problems: the role of group decision support. London: Sage: $48-52$.

Eden C (1995). On evaluating the performance of 'wide band' GDSSs. European Journal of Operational Research; 81: 302-311

Eden C, Ackermann F, Cropper S (1992). The Analysis of Cause Maps. Journal of Management Studies; 29: 309-324.

Eden C, Ackermann F (2004). Use of soft OR models by clients - what do they want from them? In M. Pidd (Ed). Systems modelling: theory \& Practice, Wiley, Chichester: 146-163.

Eden C, Huxham C (2006). Researching Organizations using Action Research. In W. Nord (Ed) Handbook of Organizational Studies. Sage, Beverley Hills, CA: 388-408.

Eden C, Ackermann F, Bryson JM, Andersen DF, Richardson GR, Finn C (2008). Integrating Modes of Policy Analysis and Strategic Management Practice: Requisite Elements and Dilemmas. Journal of the Operational Society; 60: 2-12.

Flood R, Jackson M (1991). Creative Problem Solving: Total Systems Intervention, Wiley, London. 
Franco A, Lord E (2011). Understanding multi-methodology: Evaluating the perceived impact of mixing methods for group budgetary decisions. Omega; 39(3): 362-372.

Howick S, Eden C, Ackermann F, Williams T. (2008). Building Confidence in Models for Multiple Audiences: the Modeling Cascade. European Journal of Operational Research; 186: 1068-1083.

Howick S, Ackermann F (2011). Mixing OR Methods in Practice: Past, Present and Future Directions. European Journal of Operational Research;215: 503-511.

Howick S, Eden C (2011). Supporting Strategic Conversations: The Significance of a Quantitative Model Building Process. Journal of the Operational Research Society; 62 (5): 868-878.

Huxham C, Cropper S (1994). From Many to One - and Back. An exploration of some components of facilitation. Omega 22(1): 1-11.

Jackson MC (1999). Towards coherent pluralism in management science. Journal of Operational Research Society; 50(1): 12-23.

Midgeley G, Cavana RY, Brockleby J, Foote JL, Wood DRR, Ahuriri-Driscoll A (2013). Towards a new framework for evaluating systemic problem structuring methods. European Journal of Operational Research; 229(1): 143-154.

Miles and Huberman (1994) Qualitative Data Analysis. Beverly Hills. Sage.

Mingers J (1997). Multi-Paradigm multimethodology. In Multimethodology: Theory and Practice of Combining Management Science Methodologies. J. Mingers and A. Gill (Eds.), Wiley, Chichester: 120.

Mingers J (2000). Variety is the spice of life: combining soft and hard OR/MS methods. International Transactions in Operational Research 7; 673-691.

Mingers J (2001). Multimethodology - Mixing and Matching Methods. In. In: Rosenhead J, Mingers J, (Eds.). Rational Analysis for a Problematic World Revisited. Wiley: Chichester:289-309.

Mingers J (2003). A classification of the philosophical assumptions of management science methods. Journal of the Operational Research Society; 54: 559-570.

Mingers J, Brocklesby J (1997). Multimethodology: Towards a Framework for Mixing Methodologies. Omega; 25(5): 489-509.

Mingers J, Gill A (1997). Multimethodology: The Theory and Practice of Combining Management Science Methodologies. Wiley: Chichester.

Morgan J, Howick S, Belton V (2015). A toolkit of designs for mixing discrete event simulation and system dynamics. Submitted to European Journal of Operational Research.

NERC Report (2010) Reliability Considerations from the Integration of Smart Grid, http://energy.gov/sites/prod/files/oeprod/DocumentsandMedia/SGTF Report Final.pdf 
Orlikowski W J (2000). Using technology and constituting structures: a practice lens for studying technology in organizations. Organization Science, 11(4):404-428.

Ormerod R (1996). Information Systems Strategy Development at Sainsbury's Supermarkets using "Soft" OR. Interfaces; 26(1): 102-130.

Ormerod R (2014a). The mangle of OR practice: towards more informative case studies of 'technical' project. Journal of the Operational Research Society; 65 (8): 1245-1260.

Ormerod (2014b). Critical rationalism in practice: Strategies to manage subjectivity in OR investigations. European Journal of Operational Research; 235: 784-797.

Parker S, Skitmore M. (2005). Project management turnover: causes and effects on project performance. International Journal of Project Management; 23: 205-214.

Phillips LD, Phillips MC (1993). Facilitated Work Groups: theory and practice. Journal of the Operational Research Society; 44: 533-549.

Pickering A (1995). The Mangle of Practice: Time, Agency and Science. The University of Chicago Press: Chicago.

Pidd M (Ed.) (2004). Systems modelling: Theory and Practice. Wiley, Chichester

Pollack J (2009) Multimethodology in series and parallel: strategic planning using hard and soft OR. Journal of the Operational Research Society; 60 (2): 156-167.

Rosenhead J, Mingers J (2001). Rational Analysis in a Problematic World Revisited, London, Wiley.

Schultz M, Hatch MJ (1996). Living with Multiple Paradigms: The Case of Paradigm Interplay in Organisational Culture Studies. Academy of Management Review; 21(2): 529-557.

Small A, Wainwright D (2104). SSM and technology management: Developing multimethodology through practice. European Journal of Operational Research; 233:660-673.

Susman GI, Evered RD (1978). An assessment of the scientific merits of action research. Administrative Science Quarterly; 23 (4): 582-603.

Walls L, Quigley J, Houghton T, Ackermann F, Howick S (2013). Modelling Systemic Risks to Inform a Repowering Decision. ESREL 2013, Amsterdam, Netherlands.

Weick KE (1995). Sensemaking in organizations. Thousand Oaks, CA: Sage.

White L, Yearworth M, Burger K (2015). Understanding PSM Interventions Through Sense-Making and the Mangle of Practice Lens. Outlooks and Insights on Group Decision and Negotiation (pp. 1327). Springer International Publishing

Zhu, Z (2011). After paradigm: why mixing-methodology theorising fails and how to make it work again. Journal of Operational Research Society; 62(4): 784-798 